\title{
A Multidimensional Model for the Vernacular: Linking Disciplines and Connecting the Vernacular Landscape to Sustainability Challenges
}

\author{
Juanjo Galan ${ }^{1, *(\mathbb{D}, \text { Felix Bourgeau }}{ }^{1}$ and Bas Pedroli ${ }^{2} \mathbb{D}$ \\ 1 Department of Architecture, Aalto University, 02150 Espoo, Finland; felix.bourgeau@aalto.fi \\ 2 Department of Environmental Sciences, Wageningen University, 6708 Wageningen, The Netherlands; \\ bas.pedroli@wur.nl \\ * Correspondence: juagavi@gmail.com
}

Received: 16 June 2020; Accepted: 3 August 2020; Published: 6 August 2020

check for updates

\begin{abstract}
After developing a systematic analysis of the vernacular phenomenon in different disciplines, this paper presents a flexible model to understand the multiple factors and the different degrees of vernacularity behind the many processes that lead to the generation of material culture. The conceptual model offers an open, polythetic and integrative approach to the vernacular by assuming that it operates in different dimensions (temporal, socio-political, sociological, locational, epistemological, procedural, economic and functional), and that the many attributes or characteristics included in those dimensions are all relevant but not strictly necessary. The model is intended to facilitate a more methodical and rigorous connection between the vernacular concept and contemporary discourses on sustainability, resilience, globalization, governance, and rural-urban development. In addition, and due to its transdisciplinary character, the model will enable the development of comparative studies within and between a wide range of fields (architecture, landscape studies, design, planning and geography). A prospective analysis of the use of the model in rural landscapes reveals its potential to mediate between the protective approach that has characterized official planning during the last decades and emergent approaches that advocate the reinterpretation of the vernacular as a new form to generate new collective identities and to reconnect people and place.
\end{abstract}

Keywords: sustainable development; sustainable landscape; landscape planning; globalization; rural landscapes; landscape governance; material culture; cultural landscapes; vernacular design; vernacular architecture; place-making

\section{Introduction}

The relevance of the vernacular in the evolution of material and immaterial culture has been recognized in various disciplines ranging from design, to planning, architecture, anthropology, linguistics, human geography and landscape studies. This relevance has recently gained a new impetus as the vernacular concept has been associated with emerging planning paradigms such as sustainability or resilience. Furthermore, the vernacular has also been introduced in contemporary discussions about models of governance, new potential connections between people and place, globalization, and novel possibilities for individual or collective agency [1-6].

In this context, the vernacular concept has been approached by different authors in multiple ways and has been assigned different meanings. Moreover, sporadically, the concept has been explained through different models and has been used to support contrasting ideologies or worldviews [5,7]. This situation makes it difficult to frame the vernacular concept with accuracy. At the same time, this reveals the potential of this elusive, cross-cutting and flexible concept to help us understand better how material culture is generated and how connections between people and place are established. 
The vernacular as a phenomenon is still ubiquitous and common. We should keep in mind that a vast majority of the constructed buildings and urban settlements in the world, especially in developing countries, do not follow the normative paths that characterize canonical architecture and regulated planning. According to Rapoport [8], a small fraction of buildings are designed by architects, and according to the United Nations [9], 25\% of the world population live in settlements that are not formally planned. In a broader sense, this means that the evolution of the landscape is still strongly characterized by unregulated processes. Moreover, following the transition towards industrial, post-industrial, and digital societies, new meanings, agendas, and challenges have been incorporated worldwide into discussions on the vernacular. In this new framework, issues such as loss of cultural diversity, deterritorialization, unsustainable development and decreasing resilience are now part of vernacular agendas [3].

In many disciplines, an evolution of the concept of the vernacular can be traced. Until the end of the 20th century, a descriptive approach based on the definition of specific attributes that differentiated vernacular objects, systems or products was followed. Later on, the formulation of more integrative definitions and models approached the vernacular as a process for the generation of a particular type of material and immaterial culture. This transition from product to process and from description to explanation has been detected by various authors and, according to Rapoport [8], follows a classical transition from a "natural history" stage towards a "problem centered" stage leading to an explanatory theory or model.

\subsection{The Vernacular as a Descriptive Approach}

Following a descriptive approach, the analysis of the qualities and attributes assigned to the vernacular concept in different design and planning fields reveals many convergences and some divergences. In architecture, Paul Oliver associates the vernacular with a type of architecture that, "comprises the dwellings and all other buildings of the people. Related to their environmental contexts and available resources, they are customarily owner-or community—built, utilizing traditional technologies. All forms of vernacular architecture are built to meet specific needs, accommodating the values, economies and ways of living of the cultures that produce them" [10]. This definition by Oliver comprises many of the key ideas behind the vernacular architecture concept: by Whom, What for and How.

Concerning the authorship or "by Whom", vernacular architecture is often associated with an architecture made and appropriated by people, anonymous, non-professionalized, self-built and displaying gestures of individuality $[1,3,11-13]$.

Regarding the purpose or "What for", vernacular architecture is usually linked with the ordinary, the domestic, the activities of everyday life, and the manifestation of livelihoods $[1,14,15]$.

Finally, the mode by which the vernacular architecture is generated or the "How", reveals some of the most crucial aspects of the vernacular concept and opens, at the same time, a direct connection to the explanation of the vernacular as a process rather than as a product $[3,14,16,17]$. Thus, the vernacular is described by many architectural researchers as a temporal process highly informed by previous experiences, in which trial and error permit the generation of an undocumented or unofficial knowledge [11,12], as an evolved and evolving way of doing a highly participatory architecture [1], and as a responsive and open-ended architecture informed by both conscious and subliminal decisions $[7,14]$. In addition, vernacular architecture is produced in a way that reflects the memory and identity of both individuals and communities, their socio-cultural values and socio-economic bonds, and especially their specific connections to the place $[1,7,14]$. As a result, vernacular architecture is claimed to be regionally specific, fitting both environmental and cultural site conditions, and a material expression of deep interactions between people and place $[1,11,14]$. Simultaneously, this strong connection to the site is commonly associated with the use of local resources, processes and technologies, transferring to the vernacular a self-sufficient, autonomous and almost autarchic or circular-economy character $[11,18]$. 
Similarly, the vernacular can also be linked with the place concept and, especially with place-making theories and practices [19]. Place-making can be defined as the "set of social, political and material processes by which people iteratively create and recreate the experienced geographies in which they live" [20]. Therefore, place-making implies the transformation and appropriation of the space by human beings [21] in a collective process that, according to the principles defined by Projects for the Public Space [22], would share many of the attributes assigned to the vernacular.

The use of the vernacular concept in landscape studies and landscape architecture has been strongly influenced by the evolution of the "landscape" concept itself. From mainly idealized, picturesque or rural-natural contexts, it developed into more open definitions in which the landscape is perceived as the manifestation of the interactions between people and the environment. As proposed by Rapoport [23] (p. 2), "Landscape does not refer to artistic or literal representations of the visible natural world, as it did through the nineteenth century; nor does it refer to 'natural' scenery. Rather, it refers to the integration of natural and human phenomena on a portion of the earth's surface." This idea was further advanced in the European Landscape Convention in which the landscape was defined as any "area, as perceived by people, whose character is the result of the action and interaction of natural and/or human factors" [24].

In addition, vernacular discussions on the landscape have also strongly been influenced by the "cultural landscape" concept that has been understood either as an almost redundant term or tautology, or as a specific landscape type. Thus, according to Rapoport [23] (p. 2), "all (or most) landscapes are cultural in the sense that they result from human actions on natural givens (geomorphology, hydrology, ecology, and the like) over historical time." On the other hand, according to UNESCO and the World Heritage Convention (WHC) [25], cultural landscapes are associated with designated sites or areas that are the result of the "combined works of nature and humankind" and that "express a long and intimate relationship between people and their natural environment." These cultural landscapes are divided by UNESCO into three categories (designed, organically evolved and associative) and due to their exceptional value are expected to be protected and managed through specific plans. Interestingly, the attributes of vernacular architecture strongly resonate with UNESCO's definition of the "organically evolved" cultural landscapes, since they are described as the result of socio-cultural and political "imperatives developed by association with and in response to its natural environment. Such landscapes reflect that process of evolution in their form and component features" [25]. These "organically evolved" cultural landscapes can be ascribed into two categories: relict (or fossil) landscapes and continuing landscapes. In the latter ones, the evolutionary process is still in progress but it is possible to detect significant material evidence of its evolution over time [26,27]. Nevertheless, it should be noted that the association of the vernacular with heritage and tradition opens one of the most controversial issues in vernacular studies: The risk of linking exclusively the vernacular with something anchored in the past, and needing protection, as could be the case with vanishing traditions or threatened cultural sites.

The work by J.B. Jackson offers a different approach by opposing the "political" and the "vernacular" landscape. The political landscape implies a top-down approach and the imposition of forms and functions unrelated to the topography and culture of the place $[28,29]$. Alternatively, the vernacular landscape evolves as a non-regulated and unplanned entity without visible signs of "political" history, as something emerging from the haphazard and from a pragmatic adaptation to the circumstances and habits developed over time. In addition, local-custom, continual and incremental adjustments, logics of the small economy and a certain ephemeral or evanescent character emerging from everyday life are presented as additional attributes of the Jacksonian vernacular [29-31]. Moreover, according to Jackson [30], and following the domination of the political landscape in the past, a new vernacular could be emerging as a consequence of the generation of lighter and more mobile societies. Freedom is perceived in these flexible communities as a primary value associated with changing and fluid meanings of the place.

The study of the use of the vernacular concept in other disciplines offers new, critical and explorative insights. Hubka [32] claims the value and validity of the vernacular in architecture as 
a full exercise of design and rejects the idea of the vernacular as unconscious design generated by spontaneous adaptation and naturalistic determinism. In his analysis of vernacular creativity in new media, Burgess [4], adheres to the contextual specificity, self-learned, amateur, folk, popular, common, locally and traditionally resourced, ordinary, not-institutionalized and ubiquitous character of the vernacular. However, at the same time, Burgess introduces new dimensions in the discussion by highlighting the importance of individual agency in vernacular processes, their connection with the definition of new dominant and marginal identities or the specific linkages between creators, synthesizers, and consumers in vernacular media. Moreover, the same author claims that there is an apparent connection between the "politics of the cultural" and the vernacular, perceived by many as a "category of cultural practice with strong political overtones" [4] (p. 30).

Some of the contemporary discourses about the vernacular can also be linked to popular and mass consumption practices, to new industrial aesthetics as discernible in the architecture of the Smithsons, and Rogers and Foster, or to the mass-produced domesticity of the kitsch, "ugly and ordinary" (see references to Umberto Eco and Venturi in [1]). On the other hand, and in opposition to the understanding of the vernacular as the language of the masses, the vernacular emerges also as the voice and vehicle of insurgence. This latter approach has been articulated through different movements in which the amateurish, unsanctioned, incremental and unofficial character of the vernacular has been socially and politically articulated through new forms of activism or even subversive actions. These can take the form of "guerrilla urbanism", "DIY urbanism", "city repair", "pop-up urbanism" or "grassroots urbanism", and according to Lydon et al. [6,33], can be grouped under the "Tactical urbanism" concept. Furthermore, Oli Mould [6] reflected critically about this type or unregulated urbanism and its paradoxical alignment with the paradigms of the "Creative City" and the "Rise of the Creative Class" $[34,35]$ that it was trying to contest. Consequently, Mould advocates the value of the new vernacular movement as a tool to challenge the neoliberal city and to reconnect people and place (cities) by empowering people through new ways of individual and collective agency [6].

The analysis of the vernacular concept in planning opens an apparently oxymoronic contradiction. Can the vernacular be planned? Thus, Donovan and Gkartzios, in their text "Architecture and Rural Planning: Claiming the Vernacular" [5], recognize the risks of a nostalgic, and purely conservative approach to the vernacular in active rural areas. They frame their dynamic approach to an evolving vernacular between two theoretical paradigms: the Critical Regionalism as proposed by Frampton, and the Neo-endogenous rural development theory as proposed by Ray [36,37]. Within this framework, the vernacular becomes a way of action and collaborative governance and a method of place-making; in other words, the vernacular approach "not only seeks to translate a local culture into physical form or structures, but, most importantly, to translate it into collaborative governance" [5] (p. 342).

\subsection{The Vernacular as a Process and as a Model}

Rapoport, in his rich and seminal texts, links different design and planning disciplines under a common model explaining the generation of vernacular environments $[8,38,39]$. The proposed model provides a deeper and metalevel understanding of the vernacular phenomenon and tries to overcome the taxonomic and descriptive narratives that have often characterized vernacular studies and that have usually led to a "learning by copying" approach. Conversely, Rapoport [8] aims at a "learning by analyzing" approach by identifying the key characteristics of vernacular products and processes. In particular, the proposed model supports a polythetic definition of the vernacular in which not all the identified characteristics are required to produce a vernacular process or product and that generates an open and flexible framework to study and use the vernacular. The model was proposed by detecting constant and variable aspects of vernacular environments. It was then combined with an operational framework in which the vernacular was connected to the generation of design codes, rules or schemata guiding people's choices and based on shared worldviews, values, ways of living and activity systems. The consequence of the systematic application of these codes or rules by people was the definition of recognizable styles and patterns and, ultimately, the configuration of vernacular 
environments or landscapes conceptualized by Rapoport as organizations of space, time, meaning and communication $[7,8,17,23]$.

Interestingly, Rapoport's conceptualization of the vernacular as both a process-product and a model was able to support his studies on spontaneous settlements, cultural landscapes, architecture and design and, at the same time, incorporated most of the attributes identified by other researchers. In addition, his abstract approach opened new connections and bridges to systems theory and social and environmental sciences.

Similarly, other authors have also emphasized the importance of studying the vernacular as both a dynamic process with evolving and open-ended products, and as a particular type of design process occurring in specific circumstances and through specific pathways. As indicated by Upton [40] (p. 2), "Some of the best studies in vernacular architecture are characterized not by the kinds of buildings that they treat but by how they go about it." This approach unlocks the vernacular to current and future design practices and, simultaneously, promotes an epistemological investigation on how the vernacular is generated $[3,4,16]$.

Furthermore, the introduction of new factors in the investigation of the vernacular can generate new possibilities for the definition of more integrative models. For instance, these models could explain the vernacular through consumption-production processes [1]; models of governance and power relationships [5]; linguistic structures and grammars [41], or the adaptation of standard solutions to specific contexts by enriching the design vocabulary and the considered factors [42]. Nevertheless, the existing literature reveals that attempts to combine and integrate all these factors into synthetic models are extremely rare.

\subsection{New Agendas and Challenges for the Vernacular}

During the last decades, research agendas on the vernacular have widened and been connected with a range of new and global challenges such as: globalization, loss of bio-cultural diversity, disconnection between cultures and places, deterritorialization, consumerism, ethnic revitalization, management and manufacturing of heritage, climate change, depletion of resources, natural disasters, rapid technological development, urbanization, lack of housing, social and environmental justice, and rural development, as well as with the not always straightforward and evident linkages between the vernacular, and the sustainability and resilience concepts $[3,16,18]$.

Sustainability and resilience have progressively emerged as umbrella concepts embracing the systemic and complex character of socio-ecological systems and their multiple social, cultural, political, environmental, and economic dimensions. These two concepts can be perceived "as overarching and guiding frameworks, setting dynamic goals or processes for the evolution of socio-ecological systems and supporting systemic and transdisciplinary ways of thinking" [43] (p. 9). In this context, research on the vernacular can support the development of new strategies of resilience towards sustainability [18].

Accordingly, vernacular architecture research has been widely connected and justified in terms of its potential contribution to the development of more sustainable buildings. In this endeavor, the identification of formal and functional factors affecting the sustainability of traditional and contemporary buildings has been crucial, and has been especially linked with studies on energy and materials cycles $[11,12,16,42,44]$. The overall conclusion of most of these studies was that by being specifically designed for the specific conditions of each place and by responding to the availability of local resources and local ways of living, vernacular approaches could make a positive impact in the development of more sustainable architectures. Furthermore, the capacity of the vernacular to respond to the evolving conditions of the environment has been associated with an intrinsic and connatural sustainable and resilient character [3]. This claim could also be supported by the close connection between the vernacular and the fulfillment of individual and collective needs through an optimized use of resources and functions. However, the linkage between the vernacular and the sustainable or resilient still needs to be fully understood [3]. In addition, globalization and deterritorialization are also recurrent challenges in many vernacular research agendas. According to 
Umbach and Hüppauf [2], if modernity is about "nomadic territorialization" and the domination of time over space, the vernacular has to be reconsidered or reinterpreted in this new context rather than being presented as an antagonist concept or as pure deterritorialization. These ideas resonate with new vernacular expressions associated by Jackson with lighter societies and more ephemeral material cultures $[29,30]$, in which a temporary and deserted house can be seen as a "a chrysalis from which its inhabitants have happily escaped to some brighter or more alluring prospect" [28] (p. 97). Furthermore, the unclear connections between people and places in a globalized world challenge the physical "group boundaries" that, according to Rapoport [8], sustain the generation of identifiable vernacular spatial patterns and local identities. However, the introduction of new sustainability and socio-cultural agendas with strong links to the place might counterbalance the proliferation of delocalized material cultures. This hypothesis could be linked with the principles of critical regionalism, in which the physical and cultural environment is expected to inform design processes more deeply [1,5,36,45]. In addition, new theoretical and methodological approaches to planning can emerge and generate new spaces for the vernacular, for instance, by promoting endogenous regional and local metabolisms, circular economies or more local patterns of consumption-production $[1,5,46,47]$.

The political and governance dimension of the vernacular has also gained increasing relevance in recent research. This is the logical consequence of the deep interconnection between vernacular processes and socio-political structures. Thus, Glassie [46] considers that the close dialogue implicit in vernacular processes promotes more egalitarian relationships. Similarly, Jackson [28] defines the vernacular landscape in opposition to the political landscape, and most of the new politics of the vernacular are defined in relation to new models of governance and socio-economic relations both between people and between people and place [4]. In fact, the unclear, but commonly accepted dichotomy between modernity and tradition has affected the perception of the vernacular and its political use. As exposed by Umbach and Hüppauf [2] (p. 2), “The political instrumentalization of the vernacular in the hands of the critics of globalization has a tendency to solidify that which we want to define as fluid and constructed .... It entails a nostalgic idealization of a past that actually never existed." Moreover, the socially conservative use of the vernacular concept has sometimes been (mis)appropriated in order to support the construction of regional and national identities based in a presumed innate and indissoluble connection between people and place. On the other hand, most of the new politics of the vernacular have emerged as a reaction to dominant neoliberal and capitalist models. These new politics of the vernacular propose more horizontal and collaborative ways of governance and design [5]. They advocate the reconnection between people and place through different types of actions and ideas such as craft movements, decentralized production, reclamation of material culture, resistance to global capitalism, or the recuperation of everyday domestic labor and productive leisure $[4,6]$.

The future of rural communities and the evolution of rural landscapes constitute another challenge within the vernacular research agenda. Even in an era in which the existence of the "rural" is questioned, rural areas concentrate some of the most intense and lasting vernacular processes such as rural constructions and agricultural techniques. The abandonment or rapid transformation of rural landscapes has become especially critical and has been recognized and addressed at international, national, and regional levels $[24,25]$. In fact, the management of rural areas has epitomized the dialectical tensions between protection and transformation, continuity and disruption, tradition and modernity. In this context, the generation of new discourses approaching the landscape as a process tries to reconcile these apparently conflicting forces, and repositions the vernacular in this new conceptual map. Thus, and as suggested by Donovan and Gkartzios [5], a tradition-based and static approach to the vernacular can lead to unexpected results such as the commodification or gentrification of the countryside in order to provide "idyllic" images for the urbanites. It can lead to the apparent oxymoron of preserving the vernacular through regulation and policies defined from outside in order to preserve the character and identity of a particular landscape. This last remark evokes Rapoport's reflection on cultural landscapes in the sense that they "approximate, however imperfectly, some ideal notion of ideal 
people living ideal lives in an ideal environment" [23]. The key question would be how much of this ideal rural construct is now defined from outside.

\subsection{Research Questions and One Key Remark}

The reviewed literature reveals that despite the many descriptions of vernacular phenomena, there is a need of integrative models combining the socio-cultural, political, economic, locational and epistemological conditions and factors explaining its occurrence. Due to their cross-cutting and conceptual character, these potential models could be applicable to the many fields or disciplines participating in the generation of material (e.g., architecture, design) and immaterial (e.g., cultivation techniques, literature) culture through vernacular processes. Furthermore, these models should, at the same time, facilitate the development of comparative and more systematic studies of the vernacular within and across disciplines, and between different historical or geographical contexts. In addition, the identification of the critical conditions and factors involved in the occurrence of the vernacular would enable a more consistent connection with some key concepts and challenges affecting the evolution and management of socio-ecological systems such as sustainability, resilience, globalization or rural development. Hence, the research question to be answered in this paper is formulated as: Can vernacular phenomena be explained through a synthetic and abstract model? Secondary questions include whether such a model can facilitate a more consistent and comparative study of vernacular phenomena within and across disciplines, and whether that model can facilitate a clearer connection between the vernacular concept and current agendas on sustainability, resilience, and other global challenges. As a prerequisite, the conceptual model is intended to explain, and not regulate the vernacular, since a regulatory approach would be inherently contradictory to the vernacular concept.

\section{Methods}

A model can be described as "something such as an object, plan, or set of rules that is used to show what something else is like or how it works" (Cambridge Dictionary) or as a "description or analogy used to help visualize something that cannot be directly observed" (Merriam-Webster Dictionary). Therefore, models imply a certain level of simplification of a complex and diverse reality and are usually developed with a special focus on some specific aspects of that reality and with explanatory or predicting purposes. Models are a representation of a diverse and often unpredictable reality. As explained by Rapoport in his seminal text, "Vernacular Design as a Model System", "Model systems are highly versatile. They can be used to test existing theory, to develop unified theories, to generate hypotheses, and to synthesize and integrate material from various sources and disciplines, to reveal unexpected connections, clarifying highly general processes, such as evolution" [8] (p. 185). Moreover, model systems can help us to define the domain or ontology of the studied subject, to advance in conceptual and theoretical studies by overcoming descriptive and taxonomic approaches and, consequently, to generate deeper, broader, and more flexible learning processes on the studied phenomenon.

As indicated by Gwendolyn Wright and suggested directly or indirectly by many other authors working on vernacular research, "We are dealing with constructions, almost pure inventions, inflected by self-serving ideological agendas about the present" [48] (p. 47). We adopt this constructivist approach, in the sense that we have addressed the vernacular concept in our proposed model as a socially built construct.

The development of the proposed model combined both inductive and deductive research strategies through the abductive approach formalized by Deming and Swaffield [49]. As displayed in Figure 1, the inductive part was based on specific observations of the studied phenomenon (in this case, the different attributes or characteristics assigned to the vernacular in the literature of different disciplines). The deductive part was based on the identification of the key dimensions or domains of the vernacular after examining the key themes in the analyzed literature and the main dimensions or domains in the study of socio-ecological systems, sustainability and resilience. These two research 
strategies retrofitted each other since the attributes emphasized the importance of some domains (for instance, the self-learning attribute of the vernacular revealed the existence of an epistemological dimension), and vice versa, the domains suggested the need of more specific attributes (for instance, the economic dimension of the vernacular suggested the importance of formalizing more clearly the vernacular in economic terms). In addition, the final model was also connected with the key societal challenges associated in the consulted literature with current and future agendas for the vernacular (e.g., sustainable and resilient development, globalization or urban/rural development).

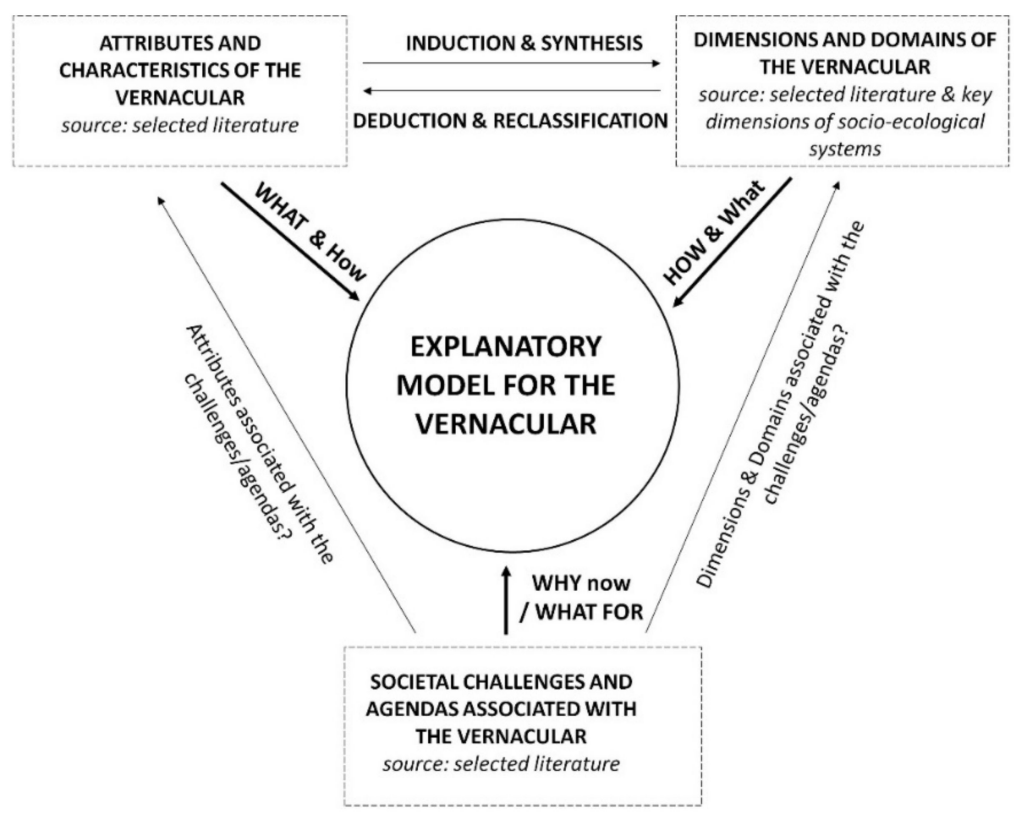

Figure 1. Methodological structure of the conducted research and of the elaboration of the model.

The conducted research was organized in the following steps:

STEP 1 Literature review:

1.1 Identification of keywords for the study of the vernacular, with a specific focus on vernacular landscapes and closely related concepts.

1.2 Search and selection of the most cited or relevant articles, papers and texts for the identified keywords. As explained below, this search was implemented using different databases, primarily Google Scholar, and secondarily, Scopus, JSTOR, and Springer.

1.3 Identification in the selected text of the attributes associated with the vernacular, the dimensions or domains used for its study, and the main societal challenges that justified the research conducted in each text. In addition, special attention was paid to any mention of explanatory models. Attributes refer, in this research, to characteristics or adjectives associated with vernacular processes or products. Dimensions or domains refer to different facets of a complex phenomenon, and in this research, they also operate as umbrella and complementary concepts grouping different types of attributes. The identified challenges include generalized problems affecting current societies, and in this research, they frame and justify the need of investigating the vernacular. Finally, models refer, in the conducted research, to the formalized and integrated explanation of the different factors and dimensions involved in the occurrence of the vernacular.

STEP 2 Synthesis and Construction of the model:

2.1 Analysis and synthesis of the attributes identified in the consulted literature.

2.2 Deduction of the key dimensions or domains associated to the vernacular in the reviewed literature and included in the main frameworks used for the study of socio-ecological systems. 
2.3 Analysis of the main societal challenges associated in the reviewed literature with vernacular phenomena.

2.4 Integration of the domains and attributes in a combined model explaining the occurrence of vernacular phenomena and connecting them with key societal challenges.

Since the focus of the conducted research was on the vernacular generation of material culture with a special emphasis on the landscape, the search of texts for the literature review was based on the following keywords: vernacular landscape, vernacular architecture, vernacular design and vernacular models.

The literature search was developed with the help of the bibliometric free software, Harzing's Publish or Perish version 7.22 (PoP). A combined query with the four listed keywords was built using Google Scholar database. The results were ordered according to the number of citations and the 300 first texts from the list were preselected. This implied that older texts might have been indirectly favored since they have had more time to accrue citations.

In the first round of refining the corpus of literature, the titles of the 300 preselected texts were analyzed and the following publications were excluded: (1) those with full-texts that were not in English, Spanish, or French; (2) those that, according to their title, dealt with case studies or particular locations (rather than general approaches to the vernacular concept); and (3) those that did not focus on expressions of material culture (e.g., publications focused on linguistics, literature, archaeology or economy). This selection resulted in 68 texts out of the 300 initially preselected.

The second round of the selection process was based on the examination of the abstracts of the 68 remaining texts. In addition to the criteria used in the first round, the following criteria were used: (4) emphasis on the definition of general attributes of the vernacular; (5) association of the vernacular with global and sustainability challenges; and (6) conceptual approach to the vernacular concept. In addition, texts from the same authors were carefully examined to avoid overlaps. After this second round, 23 texts remained in the list and became the main corpus of literature.

In order to detect additional texts linking the vernacular concept with current global challenges, a supplementary search was conducted in Google Scholar using the following keywords: vernacular and sustainability, vernacular and resilience, vernacular and governance, vernacular and politics, vernacular and globalization, and vernacular and cultural landscapes. Many of the most cited texts detected in this additional search were already included in the 23 titles of the main corpus of literature. However, 5 additional texts were added to the corpus since they provided new links with the resilience concept and with sustainable architecture. Additionally, and in order to frame the vernacular concept within the most internationally recognized landscape planning and cultural landscapes agendas, four official documents were added (European Landscape Convention [20], Word Heritage Convention [21], the Venice Charter [22], and the World Heritage Cultural Landscapes Handbook for Conservation and Management [23]). The final result of the selection was a list of 32 texts which informed step 1.3 of the conducted research.

\section{Results}

The systematic analysis of existing definitions of the vernacular concept in the selected literature was carried out in order to identify in each text the main attributes, dimensions, and societal challenges or agendas presented by the consulted authors to frame their argumentations.

Most of the identified attributes of the vernacular were defined in opposition to other modes of generation of material culture. In fact, and as suggested by Williams and Young [41] in their study about sociolinguistic models and studies in vernacular architecture, the theory of binary opposites (Levi Strauss) could explain the unconscious development of narratives through the conflict of opposing forces (e.g., vernacular versus modern or vernacular versus globalization). However, this dichotomist approach has been heavily contested by different authors who ask for a more flexible approach to the vernacular through "vernacular modernism" [2] or polythetic definitions [8]. 
Interestingly, the key attributes assigned to the vernacular were largely shared in different disciplines, revealing a common and cross-cutting understanding of the concept. However, the articulation between those attributes was often unclear, probably as a consequence of placing a special focus on the description of the product rather than on the explanation of the process. Conversely, the texts and authors approaching the vernacular through processes and models offered a more systemic and causal explanation of the vernacular regardless of the discipline.

In particular, a synthetic analysis of the reviewed literature suggests that the vernacular can be associated with the following eight dimensions or domains: temporal, socio-political, sociological, locational-contextual, epistemological and cognitive, procedural, economic, and functional. As displayed in Table 1, these dimensions were used to reorganize the multiple attributes and counter-attributes found in the literature. Additionally, in its fourth column, Table 1 includes the main concepts that were used in the consulted literature to connect the vernacular with potential solutions to global challenges (see numerical codes from the first column in the last column of Table 1). The proposed eight dimensions can be also understood as types of factors or causes explaining the occurrence of the vernacular.

Table 1. Condensed list of dimensions and attributes of vernacular phenomena, and linkages to potential solutions to global challenges as extracted or deducted from the reviewed literature.

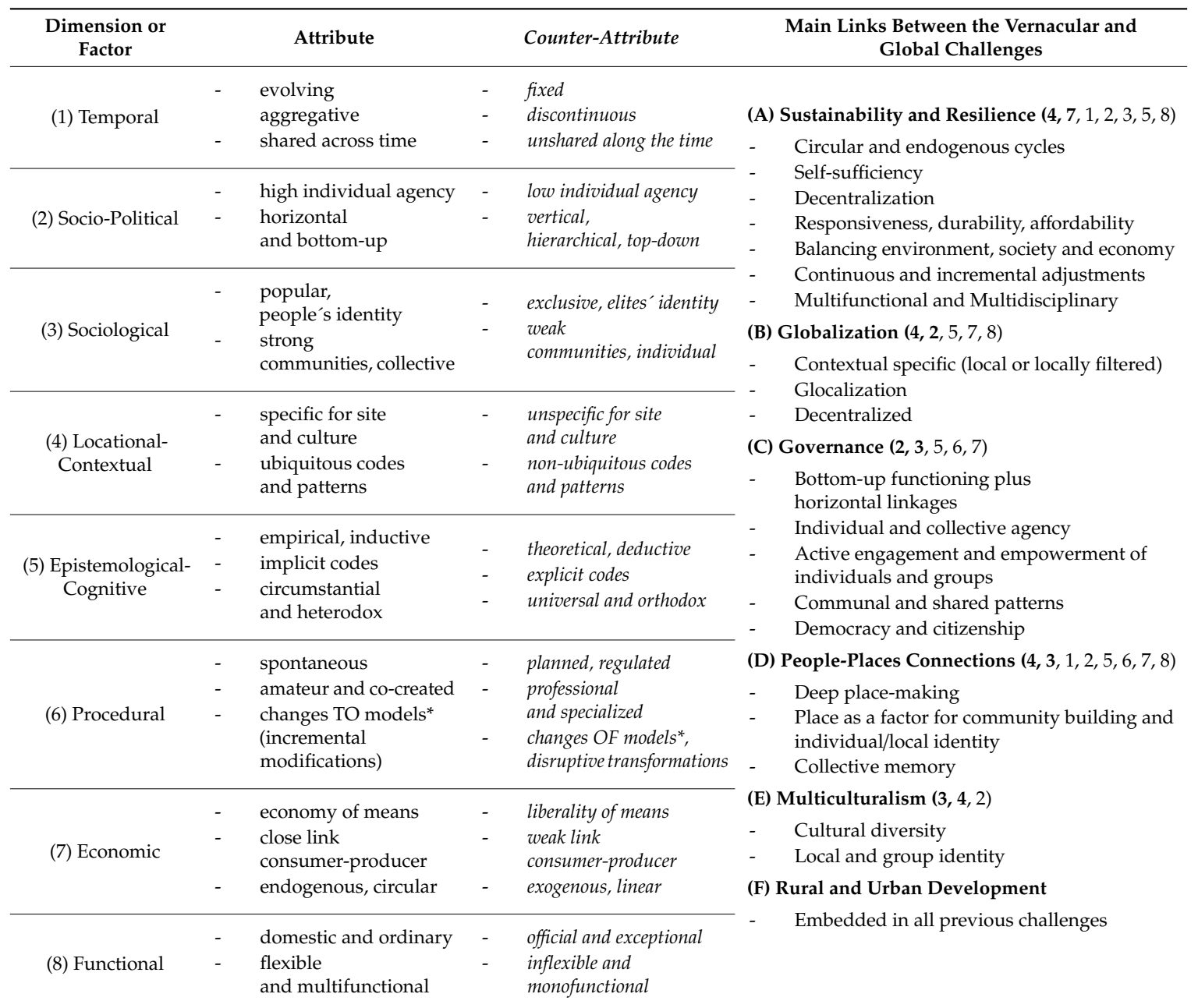

* as per Rapoport [8]. Note: Numerical codes refer to proposed dimensions of the vernacular and their attributes; alphabetical codes refer to key global challenges and potential solutions connected to the vernacular. Bolded numbers in last column indicate stronger links. 
The Temporal dimension includes the temporal conditions required for the occurrence of vernacular phenomena. The vernacular is associated with evolving cultural processes shared and transmitted across time, usually between different generations although time spans might be shortening as a consequence of industrialization and digitalization. The vernacular spreads spatially and temporally through aggregative patterns due to its collective and unplanned nature (see also the sociological, locational and procedural dimensions).

The Socio-Political dimension addresses the socio-political conditions favoring the occurrence of the vernacular. These conditions are based on a high level of individual and collective agency, understood as the capacity of individuals and groups to transform and manage their environment or to generate the elements or objects that they need. Indirectly, this implies horizontal and bottom-up processes emerging from the people and leading to the generation of culture.

The Sociological dimension considers how the development, structure and functioning of human societies can foster the vernacular. According to the examined literature, the vernacular expresses and promotes the development of common people's culture and collective identities through the generation of integrated communities that share worldviews, values, interests, ways of living and codes.

The Locational-Contextual dimension contains one of the most agreed conditions or characteristics of the vernacular: the specific and deep connection with the biophysical and cultural environment. This connection generates identifiable and ubiquitous patterns, which, in the case of material culture, can also characterize the local landscape. The ubiquity of the vernacular relies on the presence within a particular area of people who share the same codes and practices in their interaction with the environment. Due to the multidimensional character of the vernacular, the locational-contextual dimension is strongly connected with the economic dimension (local resources and knowledge are essential in the generation of vernacular products and processes) or with the sociological dimension (local communities construct their identity through collective place-making and through the definition of a shared culture).

The Epistemological-Cognitive dimension explains the vernacular phenomenon in terms of the processes that permit the generation, accumulation and transmission of vernacular knowledge. According to the consulted literature, vernacular knowledge relies on trial and error or empirical methods. These methods mainly operate in inductive ways and imply the progressive and collective definition and adjustment of shared models and practices. Hence, vernacular knowledge is usually based on implicit codes that are seldom formalized in scientific theories or explicit models. Due to its domestic and practical character, the vernacular is generated in response to the local circumstances, and because of its pragmatic and heterodox character, it allows for high levels of hybridity, evolution and adaptation.

The Procedural dimension is strongly connected with the epistemological-cognitive and socio-political domains presented above and refers to the specific way in which vernacular processes occur and vernacular products are produced. Firstly, the vernacular has an unplanned or spontaneous character that is the consequence of high levels of individual agency. Secondly the vernacular is progressively defined by active individuals within integrated communities that promote and aggregate independent actions through collective and shared codes $[7,8,17,23,39]$. Moreover, due to the collective and co-created character of vernacular models, they tend to have a temporal continuity and adaptive capacity. They are more prone to progressive or incremental modifications than to radical or disruptive transformations (variations OF the model instead of variations TO the model according to Rapoport [38]).

The Economic dimension incorporates the production-consumption aspect of the vernacular and its relationship with the management of resources. Due to its popular, ordinary and domestic character (see sociological and functional dimensions), the vernacular is commonly associated with an economy of means that implies the use of easily available resources, techniques and knowledge, and a close connection-or even coincidence-between producer and consumer [1,46]. In a globalized world, availability might not necessarily mean proximity, but still, the vernacular relies on the locally 
and easily accessible. These two conditions, local availability and close connection between producer and consumer/user, resonate with some of the principles of circular economy, endogenous cycles, sustainable metabolisms, and in a wider sense, with the recalibration of global and local flows through the glocalization concept [50].

Finally, the Functional dimension addresses the activities and functions of the vernacular. These activities are usually related to the domestic, the everyday and the ordinary, in which individuals find more space for personal agency (see Socio-Political dimension) and more motivation and opportunities for personal involvement. The space of the vernacular is therefore strongly connected with the most constant and frequent elements and activities in people's daily lives and with the development of collective identities (see Sociological dimension). Following the economy of means principle (see Economic dimension), the vernacular tends to optimize resources and solutions by making them more multifunctional, flexible and adaptive.

All presented dimensions are part of the proposed multidimensional model explaining the conditions for the occurrence of the vernacular. As clarified in the paragraphs above, these dimensions are interconnected. There are synergic or inhibiting effects between dimensions and not all of them need to be fully expressed to generate a "vernacular phenomenon". For instance, assuming that spontaneous settlements can be a contemporary example of vernacularity [39], it would be pertinent to investigate the origin of all the materials employed in their construction. We would probably find a vast array of products manufactured worldwide, which, despite their external origin, were easily available for local people in their local context. Similarly, many other dimensions of the proposed model can gain or lose importance in a given process or product without denying a certain level of vernacularity to the final product.

Therefore, rather than a white and black, binary or dualistic model, the proposed model suggests that the vernacular operates in a wide range of grays and is informed by different types of factors, presented in the model as the "dimensions" or "domains" of the vernacular. In this case, Table 1 displays in its second column, the specific attributes that characterize vernacular modes of cultural production, but these attributes could be easily modified to represent other modes such as highly regulated design and planning practices.

Figure 2 provides a graphic representation of the proposed model in which the dimensions are each given the same weight. They could be measured from 0 to $10 ; 10$ being the hypothetical score for the ideal or archetypical vernacular according to the attributes defined in Table 1 . In fact, any material culture phenomenon could be represented in the proposed spider graph: The total area included within the representation of the studied phenomenon would be then an approximate indicator of its level of vernacularity (see examples in Figure 3).

In addition, the proposed model can facilitate a more systematic and comparative study of vernacular phenomena, may those be objects, patterns, settlements or landscapes. This possibility resonates with Rapoport's proposal of shifting from descriptive analysis to overarching theories and models for the vernacular [8].

As an illustrative example, the proposed model has intuitively been used in Figure 3 to evaluate the level of vernacularity in three different types of rural houses (see colored areas surrounded by polygons) and to identify which factors were more critical for achieving those levels of vernacularity. Thus, the total area included inside each polygon would be an indicator of the overall level of "vernacularity", whereas the scores in each dimension would tell us which factors add or detract more to the total vernacularity. In addition, Figure 3 reveals the need of defining, in the future, quantifiable metrics to assign precise values to each vernacular dimension. 


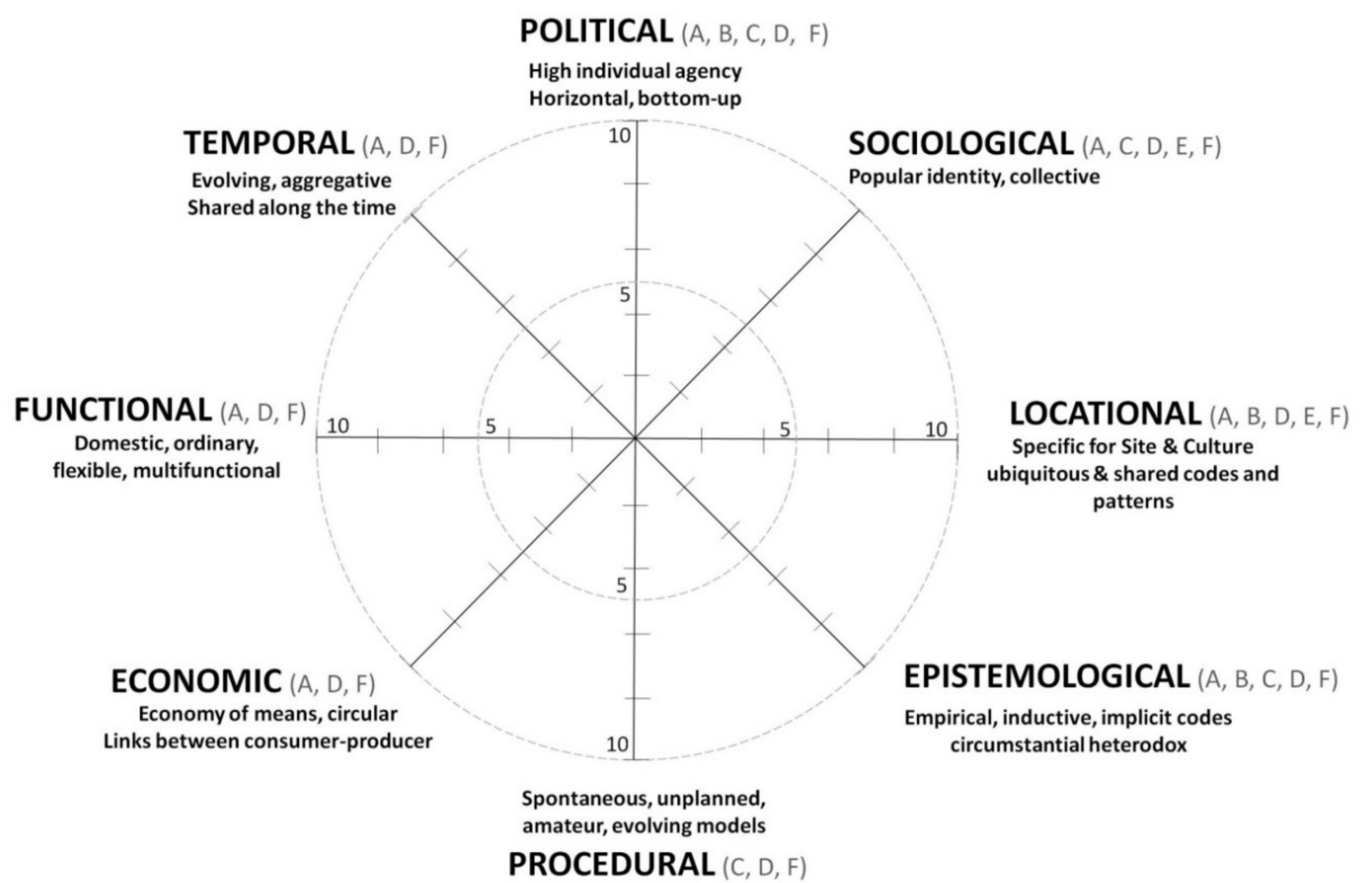

Figure 2. A multidimensional and polythetic model to study vernacular phenomena and to connect vernacular processes or practices with global challenges. Letter codes refer to global challenges listed in Table 1.

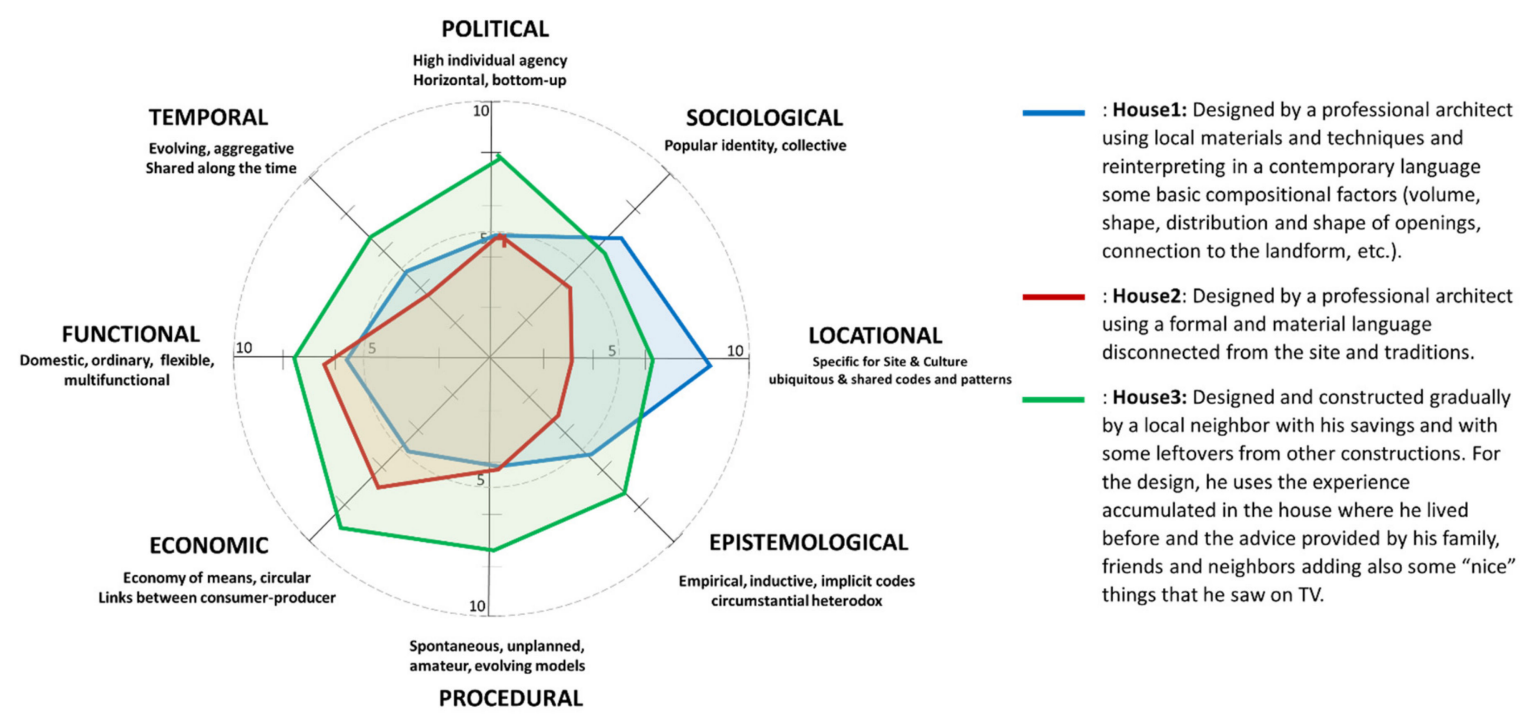

Figure 3. Approximate representation of the levels and causes of vernacularity in three different types of houses in a Mediterranean terraced landscape (Note: A more accurate representation would require the definition of metrics in future research).

\section{Discussion}

In the following subsections, the research questions which prompted the development of this article are revisited, including a critical analysis of how they are answered and how the produced results can be connected to existing theory in vernacular studies or to future lines of research. 


\subsection{A Multidimensional and Polythetic Model for the Vernacular}

The first and main research question asked whether vernacular phenomena could be explained through a synthetic and abstract model. In answer to this question, it is proposed a polythetic and multidimensional model. The polythetic quality of the model suggests that the vernacular is associated to several attributes or characteristics which occur in vernacular products and processes, but none of which is strictly necessary [8]. The multidimensional quality indicates that the vernacular depends on different dimensions or domains which can also be perceived as types of factors affecting its occurrence. Importantly, the model combines its polythetic and multidimensional qualities by grouping the main attributes of the vernacular under eight interconnected dimensions.

A critical analysis of the proposed model in the context of existing theory reveals that it responds to the ongoing transition from descriptive and product-based studies, to explanatory and process-based studies in which both vernacular products and processes are recognized as mutually dependent $[1,38]$. In addition, the model supports a shift from dualistic or monothetic approaches in which the vernacular is defined in opposition to other modes of cultural production, to more integrative, systemic and hybrid approaches, promoting deeper levels of learning on the vernacular and opening new and more fruitful connections within and between disciplines $[1,8]$.

Moreover, the proposed model does not intend to oversimplify or to regulate the vernacular (in fact, that would be antithetical to the concept), but to analyze it within a flexible space in which the vernacular can happen in multiple degrees and as a combination of different factors. Therefore, the model should be perceived as a lens to appreciate levels or types of "vernacularity" in different cultural phenomena rather than as a deterministic tool.

The conceptual approach to the vernacular implemented in the conducted research, and its formalization in a multidimensional model, opens also new topics for critical reflection. Thus, according to Umbach and Hüppauf [2] (p. 4), the vernacular cannot be dissociated from the "difference of place" and from the increasing interest that different sciences are expressing on particularity, heterogeneity and plurality, as a counterbalance to universalism, abstraction, rationalization and to the modern paradigm of generating a "life independent of place and experienced time." Moreover, the contemporary vernacular can mediate between the regional and the global and can help us recover the spatial perspective of modernity and reconnect people with place by supporting more personal experiences of the place [2]. In fact, these same authors reject the dichotomy between vernacular and modern claiming that, "The vernacular itself is one of the generative principles of the modern condition" [2] (p. 8). This proactive approach is also at the core of the proposed model, in which the authors of this paper present the vernacular as a general mode of cultural production. However, Umbach and Hüppauf delineate two possible new dimensions of the vernacular. On the one hand, the "experiential or phenomenological", on the other hand, and following the connection established by these two authors, between the vernacular and the Heimat, the "existential" [2].

One of the most contentious aspects of the presented model is the number and type of dimensions that it includes. Can they be grouped and simplified? Do we need more? In the following paragraphs, we reflect on the theoretical and practical implications of the dimensions included in the model in order to advance future research.

A critical analysis of the model reveals the key importance of the "temporal" dimension as it addresses the evolving nature of the vernacular and the time required to forge vernacular patterns $[1,8]$. On the other hand, the "socio-political" dimension is one of the most frequently mentioned in the consulted literature and can be associated with the level of individual and collective agency. This agency strongly depends on the socio-political organization of societies [2] and in contemporary discourses can foster the development of new models of governance through the active reconnection of people and place $[1,3,6]$. Paradoxically, and following the frequent ideologization of the concept, current approaches to the vernacular can sustain both highly conservative and radically transformative political agendas. 
Interestingly, these political discourses also strongly influence the "sociological" dimension of the model that addresses the connection between popular identities and the vernacular. Thus, the inhibition of horizontal social relationships through political power might affect people's capacity to construct shared identities. Moreover, in an increasingly globalized and deterritorialized world, the sociological dimension is directly linked to the definition of the spatial "group boundaries". These, according to Rapoport [8], are needed to generate shared codes linking people and place or, in a wider sense, to construct local and regional identities within the context of delocalized cultures [2]. In addition, deterritorialization and globalization affect also the "locational-contextual" dimension of the model since the vernacular is claimed to be specific for site and culture. This means that, if modernity can be described as a process of "emancipation from the restrictions of place" (Habermas as cited in [2] (p. 4)) the vernacular could be perceived as a potential counterforce.

On the other hand, in the context of highly specialized, industrialized and digital societies, the epistemological, procedural and economic processes involved in the generation of the vernacular emerge as another key topic for discussion. Thus, the proposed "epistemological" dimension refers to the empirical, circumstantial and inductive methods that lead to the generation and transmission of the implicit models that are associated with vernacular knowledge. This knowledge is also referred to as both conscious and subliminal, and as dynamically exposed to cultural weathering and hybridity [14]. In a conciliatory approach, Umbach and Hüppauf suggest that vernacular thinking complements "abstract modern categories by producing concrete shapes and cultural meaning" [2] (p. 11). Besides, the contemporary vernacular is sometimes associated with the adoption and adaptation of the material culture of the elites by the masses [1]. In that case, it would be pertinent to analyze how this "copy and paste" approach would really fit in the epistemological conditions of the vernacular.

Regarding the predominant and globalized modes of production in industrial and postindustrial societies, the "procedural" dimension of the model offers a specific window to analyze how these production modes might relate to the spontaneous and unplanned processes that characterize the development of the vernacular. Furthermore, the same modes of industrial and postindustrial or digital production can be studied from the perspective of the "economic" dimension of the proposed vernacular model. In this regard, we claim that, in addition to the economy of means, the close relationship between consumer and producer $[1,7,46]$, and the circular flow of resources between the society and the environment or within the society (socio-ecological metabolism) are prominent characteristics of the vernacular activity. Furthermore, these characteristics can be aligned with some of the precepts of the circular economy and of sustainable development as defined by Korhonen et al. [51]. Interestingly, according to Glassie [46], consumer and producer do not need to be the same person, but they should at least share an experience of participation. In a wider sense, the vernacular has also served as a basis to criticize global capitalism and neoliberal agendas. The latter would just lead to the concentration of power and capital whereas the vernacular is characterized by shared values and resources.

Finally, the "functional" dimension of the model refers to the domestic and ordinary character of the vernacular, which, in combination with the practical approach implicit in the vernacular economy of means, tend to generate flexible and multifunctional processes and products. This opens an interesting topic for reflection: the relationship between the "ordinary" and the "vernacular" in industrial and post-industrial societies. Thus, if the vernacular is linked with the ordinary or popular, the products of current mass consumption practices and their associated places would fit in this category (Umberto Eco as cited in [1]). However, if we consider other vernacular dimensions (e.g., epistemological or economic), it would be difficult to argue that the new vernacular can occur in standardized shopping malls or theme parks in which there is no knowledge generated by people and there is no connection between producer and consumer.

Some of the contradictions explained above give an additional value to the proposed multidimensional model since it creates a flexible framework to analyze the vernacular from different and cross-cutting perspectives. Furthermore, assuming that there might be no "archetypical" vernacular processes or products, the proposed model displayed in Figure 2 helps us to identify in which specific 
dimensions reside precisely the vernacularity of one particular product or process. Moreover, despite the qualitative character of the defined dimensions, the quantitative character of the overall model avoids a binary (yes or no) approach to each dimension and provides a richer and more integrative understanding of the vernacular.

In relation to the second research question proposed in this paper, the authors of this paper claim that the multidisciplinary approach followed in the identification of vernacular attributes, and the interdisciplinary deduction of the eight dimensions involved in the vernacular, give to the proposed model the capacity to be applied in the many disciplines involved in the generation of material culture (design, architecture, landscape studies or planning). On the other hand, the systematic and quantitative use of the model may also permit the development of more consistent comparative studies within (see example in Figure 3) and between disciplines. Moreover, following Rapoport's argumentation, the proposed model would specially fit in the category of those models used "to develop unified theories ... and reveal unexpected connections, clarifying highly general processes" [8] (p. 185).

\subsection{A Model Connecting the Vernacular with Contemporary Global Challenges: The Role of the Vernacular in Post-Modern Times}

Regarding the third question that prompted this research, namely, the hypothetical connection between the vernacular and the considered global challenges, Table 1 and Figure 2 indicate that most of the challenges are closely related with many dimensions of the vernacular (see numerical codes in the last column of Table 1). Consequently, most of the vernacular dimensions can be connected to several global challenges (see letter codes in Figure 2). These preliminary findings suggest that vernacular processes can help us respond to some complex challenges affecting contemporary societies.

A more comprehensive study of the connection between the vernacular concept and global challenges exceeds the scope of this paper, where the main aim was to develop a conceptual and integrated model for the vernacular. However, Table 1 already reveals some promising results. Thus, the association of the vernacular with "sustainability and resilience" in the consulted literature was strongly based on system properties shared by these two concepts such as circularity, decentralization, self-sufficiency, adaptability, responsiveness or multifunctionality. Moreover, the vernacular concept was able to integrate the environmental, social and economic dimensions that are often used to analyze sustainability and resilience, creating a promising ground for future relational studies. In fact, these connections would be almost direct for the social and economic pillars, whereas the environmental pillar could be associated with the ecological component embedded in the locational dimension of the vernacular.

Similarly, Table 1 shows how the vernacular is perceived as a potential counterforce to "globalization" by promoting more contextualized responses to societal needs, either through the definition of local solutions or through the adaption of global ones.

The connection between the vernacular and the development of "new models of governance" was mainly based on the bottom-up and horizontal processes that sustain the generation of the vernacular and, consequently, the existence of high levels of individual and collective agency in the production of material culture. Therefore, in a contemporary context, the vernacular is perceived as an opportunity for the active engagement and empowerment of individuals and groups, for the definition of new types of communal structures, and for the exploration of new ways of democracy and citizenship. Interestingly, these reflections connect to the construction of new links between people and places, and the generation of community feelings and identities through place-making.

Besides, the vernacular can also be advocated in terms of "multiculturalism" as a tool to regain cultural diversity though the generation of territorialized identities. Moreover, as indicated in Table 1, all the analyzed global challenges and the opportunities provided by vernacular processes can be applied to the last proposed challenge: rural and urban development. In fact, the proposed model could also support the definition of new solutions for rural development, especially in the management of the usually dense and valuable vernacular layer embedded in rural landscapes. These kinds of 
solutions could, for instance, favor the development or adaptation of local design codes or techniques, rather than the mere introduction of standardized ones.

A critical analysis of the results also reveals theoretical issues affecting this third research question and advancing future research. As Asquith and Vellinga [3] indicate, the vernacular can help us adapt modern and global practices to local circumstances. Thus, according to Lawrence, the principles deducted from the study of the vernacular can "be applied in professional practice to increase the sustainability of future buildings and settlements" [3] (p. 11). Nevertheless, additional studies might be needed to evaluate the utility of vernacular solutions in contemporary challenges [3]. Furthermore, these studies should also consider how new forms of vernacularity can operate in globalized and highly mobile societies.

We claim that, although the vernacular is intrinsically connected with the sustainability and resilience concepts, this connection needs to be further investigated. This is especially true if we consider that sustainability and resilience can also be associated to other (non-vernacular) modes of production of material culture, or that sustainability and resilience can operate on scales that exceed the local vernacular. These reflections can be translated into two basic questions that we would like to explore in future research: To which degree, and how sustainability and resilience can be associated to the vernacular (see some initial ideas in Table 1), and secondly, is all the vernacular sustainable and resilient?

Nevertheless, we argue that the sustainability and resilience concepts can provide a new paradigm to study and favor vernacular practices in the 21st century. Therefore, the potential of the proposed model resides in its capacity to inform a renewed use of the vernacular in the development of more sustainable and resilient societies. This potential could be implemented by taking advantage of the local, aggregative, spontaneous and unregulated character of the vernacular, and by recognizing the limitations of the vernacular to affect the complex and multiple challenges associated to global sustainability and resilience. In this regard, the Sustainable Development Goals of the United Nations might also offer a particularly fertile ground to frame future research [52].

Regarding other global challenges, the vernacular concept has acquired a new role and meaning in relation to the new power and material relationships generated by globalization. Umbach and Hüppauf argue that, despite the generalized discourse, globalization is not placeless since it depends on nodal points for the circulation of knowledge and capital. In this context, the vernacular could become a tool to define an alternative "imagination of place" [2] (p. 16). This idea resonates with Kenneth Frampton's principles on critical regionalism and his objective of resisting the homogenizing tendencies of production-consumption in a globalized world. It also corresponds to Manuel Castell's perception of globalization as a process changing our perception of place and identity $[1,53]$. Moreover, the questioning of globalization could support the definition of new links between people and place with the subsequent effects in planning and spatial politics [2]. This applies both to the development of new models of governance and to people's engagement with the place through vernacular place-making.

\subsection{About Landscapes and Rural Development}

Concerning the evolution of rural and urban areas, and more critically, the development of their landscapes, the proposed model offers a systemic and multidimensional approach to the landscape and a proactive tool to integrate the vernacular concept in rural planning. Thus, if any landscape modified or signified by humans has a cultural dimension [23,24], the vernacular could be perceived as a sub-layer within this cultural dimension, produced through the wide range of vernacular processes that can be described through the proposed model. Furthermore, the vernacular component would be as ubiquitous as the presence of people interacting or transforming the landscape through vernacular practices. The level of presence of the vernacular in the landscape was also studied by Rapoport in his article, "On Cultural Landscapes" [7], in which he proposed that vernacular elements or patterns can define either the "matrix" or the "infill" of landscapes. Interestingly, this way of interpreting 
the landscape suggests potential links with other disciplines approaching the landscape also as a spatial-temporal system (e.g., Landscape Ecology and its matrix-corridor-patch model).

Following the connection between the vernacular and the landscape proposed above, rural landscapes would display a particularly deep and ubiquitous vernacular sub-layer due to the long and intense interaction between people and place. This interaction has taken shape in both material and immaterial rural culture, for instance, through rural buildings, infrastructures, tools or agricultural techniques. However, global and local drivers of change such as urbanization, rural depopulation, land abandonment, proliferation of industrial agriculture and the introduction of standardized buildings, codes of practice or techniques, have generated an increasing interest in the preservation and management of rural heritage [54,55] and consequently, of the significant part of that heritage that is produced through vernacular processes. This interest is based on multiple socio-cultural, environmental and economic reasons that are often grouped under the overarching goal of sustainable and resilient (rural) development [56,57].

Due to their strategic, economic and cultural importance, most of the developed research on the rural vernacular has concentrated on traditional and vernacular buildings. These buildings are perceived as a key tool and asset for the reactivation and diversification of rural economies, especially through ecotourism [56]. Additionally, they are a crucial component in the definition of the landscape character, and consequently, there is an increasing research on methodologies to facilitate the consistent analysis, renovation, maintenance and transformation of rural buildings or ethno-villages [54,57]. Additionally, rigorous mapping of vernacular constructions is reported [55], as well as the development of new and deeper interactions between protected rural settlements and the environment by approaching them as complex social-economic-natural systems [58].

In a different line of thought, other authors consider critically the effects of the generalized conservative approach to the rural vernacular and explain the risks of defining a fossilized vision of the rural areas. This could readily lead to the thematization, commoditization and even gentrification of the countryside according to the interests of the urban population and to the consolidation of archetypical images of the rural while supporting idealized identities. Subsequently, these authors advocate the active re-engagement of rural communities in the definition of their landscapes in order to keep a renovated vernacular connection between people and place [5].

Regardless of the approach, the proposed model offers a multidimensional lens to read the rural vernacular, either in order to understand existing elements, processes and assemblages (e.g., landscapes) or to design their transformation or management in a vernacular way (see Figure 3).

\subsection{Future Research}

From this paper's analysis, the following six topics emerge for future investigation:

At a methodological level, it would be helpful to develop an operative system to assess each vernacular dimension included in the proposed model. Additionally, it would be essential to analyze if those dimensions cover adequately the many facets of the vernacular and if they should have a similar weight or importance in the overall evaluation of levels of vernacularity.

At an operational or practical level, the model should be tested and validated through its application in different fields (e.g., architecture, design, landscape studies) and in comparative studies within each field (e.g., different types of buildings or settlements). In addition, it would be crucial to confirm the utility of the model to connect vernacular processes with contemporary societal and socio-ecological challenges. In this regard, the preliminary connections detected in this research can offer a promising start. Besides, and in relation to the previous topic, it would be important to study how societies can generate more favorable conditions for vernacular processes and imagine how to foster and plan what, by definition, should be spontaneous and unregulated.

Finally, at a conceptual and semantic level, it would be advisable to investigate the divergent meanings and uses that the vernacular concept currently has and to analyze how these different meanings support contrasting ideologies or socio-political models. For instance, this line of research 
would help us to understand better the association of the vernacular with both conservative and insurgent discourses, or the simultaneous connection of the concept with popular mass-consumption processes and new craft movements.

\section{Conclusions}

This article has investigated the ontological, operational and functional aspects of the vernacular concept and proposes an integration of these three aspects (referred to as the "What", "How" and "What for") through a multidimensional and polythetic model. The multidimensional character of the model claims that vernacular processes and products involve eight different and interconnected dimensions: temporal, socio-political, sociological, locational, epistemological, procedural, economic and functional. On the other hand, the polythetic character of the model suggests that the many attributes or characteristics of the vernacular included in those eight dimensions are all relevant but not strictly necessary. Consequently, the model generates a flexible map to analyze and assess vernacular phenomena and to understand how or why they can display different degrees of vernacularity. However, it must be noted that the model is not intended to predefine the vernacular but to read it through an integrative lens revealing its many facets.

In addition, the proposed model responds to the increasing interest that the vernacular concept is gaining in sustainability, resilience, globalization, governance, people-place connections, and rural-urban development discourses. Moreover, the dimensions proposed in the model should facilitate a more systematic and rigorous connection between the vernacular concept and the above-listed challenges, for instance, by linking the vernacular dimensions with the classical pillars that articulate the study of the sustainable and resilient properties of socio-ecological systems (environmental, social and economic). Moreover, due to its conceptual and integrative character, the proposed model also enables the development of systematic and comparative studies within or between the many disciplines in which vernacular modes of production support the generation of material culture (architecture, landscape architecture, design and planning).

In this paper, the landscape concept plays a key role because of its systemic and multidimensional character. Simultaneously, it fosters an innovative approach to rural areas, in which the deep, ubiquitous and long presence of the vernacular clashes now directly with powerful global and local drivers of change. In this specific situation, the proposed model can become an integrative tool to look at the many dimensions of the vernacular and to mediate between the protective approaches supported by official spatial planning, and by those who advocate the spontaneous generation of new forms of rural vernacularity and identity.

Finally, the critical analysis of the model and of its application in the management of complex socio-ecological systems opens new spaces for research. Those spaces are mainly connected to the potential quantitative character of the model and the need of defining, in future research, the assessment criteria or metrics for each dimension, to the different weight that each dimension might have in the overall model and to the synergic or inhibiting effects that different dimensions can have in the joint definition of vernacular processes or products. For instance, what happens when the political dimension inhibits the generation of vernacular processes but there is a high level of locational-contextual engagement? In a broader sense, the conducted research also suggests the need of investigating more in-depth the role of the vernacular in relation to global challenges, and how the vernacular will respond to the evident discrepancies between insurgent and official approaches to the concept and to the emergence of delocalized cultures. The flexible and multidimensional character of the proposed model should easily accept to work with all these new possibilities.

Author Contributions: Conceptualization, writing, review and editing, J.G.; conceptualization and bibliographic search, F.B.; review, B.P. All authors have read and agreed to the published version of the manuscript.

Funding: This research received no external funding.

Conflicts of Interest: The authors declare no conflict of interest. 


\section{References}

1. Brown, R.; Maudlin, D. Concepts of vernacular architecture. In The SAGE Handbook of Architecture Theory; Crysler, C.G., Cairns, S., Heynen, H., Eds.; Sage Publications: London, UK, 2012; pp. 340-368.

2. Umbach, M.; Hüppauf, B.-R. Vernacular Modernism: Heimat, Globalization, and the Built Environment; Stanford University Press: Stanford, CA, USA, 2005; pp. 1-22.

3. Asquith, L.; Vellinga, M. Vernacular Architecture in the 21st Century: Theory, Education and Practice; Taylor \& Francis: Abington, UK, 2006; pp. 1-20.

4. Burgess, J.E. Vernacular Creativity and New Media. Ph.D. Thesis, Queensland University of Technology, Brisbane, Australia, 2007.

5. Donovan, K.; Gkartzios, M. Architecture and rural planning: Claiming the vernacular. Land Use Policy 2014, 41, 334-343. [CrossRef]

6. Mould, O. Tactical urbanism: The new vernacular of the creative city. Geogr. Compass 2014, 8, 529-539. [CrossRef]

7. Rapoport, A. On the cultural responsiveness of architecture. J. Arch. Educ. 1987, 41, 10-15.

8. Rapoport, A. Vernacular design as a model system. In Vernacular Architecture in the Twenty-First Century (Theory, Education, and Practice); Asquith, L., Vellinga, M., Eds.; Taylor and Francis: London, UK, 2006; pp. 179-198.

9. UN-Habitat. Streets as Public Spaces and Drivers of Urban Prosperity. Available online: http://www.uemi.net/ uploads/4/8/9/5/48950199/streets_as_public_spaces_and_drivers_of_urban_prosperity_small.pdf (accessed on 15 June 2020).

10. Oliver, P. Encyclopedia of Vernacular Architecture of the World; Cambridge University Press: Cambridge, UK, 1997; Volume 3.

11. Zhai, Z.J.; Previtali, J.M. Ancient vernacular architecture: Characteristics categorization and energy performance evaluation. Energy Build. 2010, 42, 357-365. [CrossRef]

12. Coch, H. Bioclimatism in vernacular architecture. Renew. Sustain. Energy Rev. 1998, 2, 67-87. [CrossRef]

13. Rudofsky, B. Architecture Without Architects: A Short Introduction to Non-Pedigreed Architecture; UNM Press: Albuquerque, NM, USA, 1987.

14. Heath, K.; Heath, K.W. Vernacular Architecture and Regional Design: Cultural Process and Environmental Response; Routledge: Abingdon, UK, 2009; pp. 1-7.

15. Illich, I. Vernacular values. In Shadow Work; Marion Boyars Publishers: London, UK, 1981.

16. Wahid, A. Adaptive vernacular options for sustainable architecture. J. Int. Soc. Stud. Vernac. Settl. 2012, 2, 74-85.

17. Rapoport, A. Vernacular architecture and the cultural determinants of form. In Buildings and Society: Essays on the Social Development of the Built Environment; Routledge: Abingdon, UK, 1980; pp. 283-305.

18. Dipasquale, L.; Kısa Ovalı, P.; Mecca, S.; Özel, B. Resilience of vernacular architecture. In Versus: Heritage for Tomorrow; Firenze University Press: Florence, Italy, 2014; pp. 65-73.

19. Hayden, D. The Power of Place: Urban Landscapes as Public History; MIT Press: Cambridge, MA, USA, 1995.

20. Pierce, J.; Martin, D.G.; Murphy, J.T. Relational place-making: The networked politics of place. Trans. Inst. Br. Geogr. 2011, 36, 54-70. [CrossRef]

21. Schneekloth, L.H.; Shibley, R.G. Placemaking: The Art and Practice of Building Communities; Wiley: Hoboken, NJ, USA, 1995.

22. Project for Public Spaces (PPS). Available online: https://www.pps.org/article/11steps (accessed on 8 July 2020).

23. Rapoport, A. On Cultural Landscapes. Trad. Dwell. Settl. Rev. 1992, 3, 33-47.

24. European Landscape Convention. Available online: https:/www.coe.int/en/web/conventions/full-list/-/ conventions/rms/0900001680080621 (accessed on 6 June 2020).

25. Word Heritage Convention: Cultural Landscapes. Available online: https://whc.unesco.org/en/ culturallandscape/ (accessed on 6 June 2020).

26. Goetcheus, C.; Mitchell, N. The Venice Charter and cultural landscapes: Evolution of heritage concepts and conservation over time. Change Over Time 2014, 4, 338-357. [CrossRef]

27. Mitchell, N.; Rössler, M.; Tricaud, P.-M. World Heritage Cultural Landscapes. A Handbook for Conservation and Management; UNESCO: Paris, France, 2009. 
28. Jackson, J.B. Discovering the Vernacular Landscape; Yale University Press: London, UK, 1984.

29. Lowenthal, D. Discovering the Vernacular Landscape by John Brinckerhoff Jackson. Geogr. Rev. 1985, 75, 515-518. [CrossRef]

30. Hugill, P.J. Discovering the Vernacular Landscape. Annal. Assoc. Am. Geogr. 1986, 76, 454-456.

31. Roth, E.G.; Eckert, J.K. The vernacular landscape of assisted living. J. Aging Stud. 2011, 25, $215-224$. [CrossRef] [PubMed]

32. Hubka, T. Just folks designing: Vernacular designers and the generation of form. J. Arch. Educ. 1979, 32, 27-29. [CrossRef]

33. Lydon, M.; Garcia, A. Tactical Urbanism. Short Term Action, Long Term Change; Island Press: Washington, DC, USA, 2015.

34. Yencken, D. The creative city. Meanjin 1988, 47, 597-608.

35. Florida, R. The Rise of the Creative Class: And How it's Transforming Work, Leisure, Community and Everyday Life; Basic Books: New York, NY, USA, 2002.

36. Frampton, K. Towards a critical regionalism: Six points for an architecture of resistance. In Anti-Aesthetic: Essays on Postmodern Culture; Foster, H., Ed.; Bay Press: Seattle, WA, USA, 1983; pp. 17-34.

37. Ray, C. Neo-endogenous rural development in the EU. In Handbook of Rural Studies; Cloke, P.J., Marsden, T., Mooney, P., Eds.; Sage Publications: London, UK, 2006; pp. 278-291.

38. Rapoport, A. A framework for studying vernacular design. J. Arch. Plan. Res. 1999, 16, 52-64.

39. Rapoport, A. Spontaneous settlements as vernacular design. In Spontaneous Shelter: International Perspectives and Prospects; Temple University Press: Philadelphia, PA, USA, 1988; pp. 51-77.

40. Upton, D. Power of Things: Recent Studies in American Vernacular Architecture. Am. Q. 1983, 35, $262-279$. [CrossRef]

41. Williams, M.A.; Young, M.J. Grammar, Codes, and Performance: Linguistic and Sociolinguistic Models in the Study of Vernacular Architecture. Perspect. Vernac. Arch. 1995, 5, 40-51. [CrossRef]

42. Wood, A. Sustainability: A new high-rise vernacular? Struct. Des. Tall Spec. Build. 2007, 16, 401-410. [CrossRef]

43. Galan, J.; Perrotti, D. Incorporating metabolic thinking into regional planning: The case of the Sierra Calderona strategic plan. Urban Plan. 2019, 4, 152-171. [CrossRef]

44. Tawayha, F.A.; Braganca, L.; Mateus, R. Contribution of the vernacular architecture to the sustainability: A comparative study between the contemporary areas and the old quarter of a Mediterranean city. Sustainability 2019, 11, 896. [CrossRef]

45. Canizaro, V. Architectural Regionalism: Collected Writings on Place, Identity, Modernity and Tradition; Princeton University Press: New York, NY, USA, 2007.

46. Glassie, H. Vernacular Architecture and Society. Mater. Cult. 1984, 16, 4-24.

47. Galan, J. Towards A Relational Model for Emerging Urban Nature Concepts: A Practical Application and an External Assessment in Landscape Planning Education. Sustainability 2020, 12, 2465. [CrossRef]

48. Wright, G. On modern vernaculars and JB Jackson. Geogr. Rev. 1998, 88, 474-482. [CrossRef]

49. Deming, M.E.; Swaffield, S. Landscape Architectural Research: Inquiry, Strategy, Design; John Wiley \& Sons: London, UK, 2011; pp. 5-7.

50. Smith, M. Glocalization. In The Blackwell Encyclopedia of Sociology; Ritzer, G., Ed.; Wiley Online Library: Hoboken, NJ, USA, 2007.

51. Korhonen, J.; Honkasalo, A.; Seppälä, J. Circular Economy: The Concept and its Limitation. Ecol. Econ. 2018, 143, 37-46. [CrossRef]

52. Sustainable Development Goals (SDGs). Available online: https://sustainabledevelopment.un.org/?menu= 1300 (accessed on 8 July 2020).

53. Castells, M. The Power of Identity; Wiley: New York, NY, USA, 2009.

54. Benni, S.; Carfagna, E.; Torreggiani, D.; Maino, E.; Bovo, M.; Tassinari, P. Multidimensional Measurement of the Level of Consistency of Farm Buildings with Rural Heritage: A Methodology Tested on an Italian Case Study. Sustainability 2019, 11, 4242. [CrossRef]

55. Cillis, G.; Statuto, D.; Picuno, P. Vernacular Farm Buildings and Rural Landscape: A Geospatial Approach for Their Integrated Management. Sustainability 2020, 12, 4. [CrossRef]

56. Leanza, P.M.; Porto, S.M.C.; Sapienza, V.; Cascone, S.M. A Heritage Interpretation-Based Itinerary to Enhance Tourist Use of Traditional Rural Buildings. Sustainability 2016, 8, 47. [CrossRef] 
57. Prevolšek, B.; Maksimović, A.; Puška, A.; Pažek, K.; Žibert, M.; Rozman, Č. Sustainable Development of Ethno-Villages in Bosnia and Herzegovina-A Multi Criteria Assessment. Sustainability 2020, 12, 1399. [CrossRef]

58. Zheng, S.; Han, B.; Wang, D.; Ouyang, Z. Ecological Wisdom and Inspiration Underlying the Planning and Construction of Ancient Human Settlements: Case Study of Hongcun UNESCO World Heritage Site in China. Sustainability 2018, 10, 1345. [CrossRef]

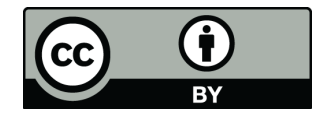

(C) 2020 by the authors. Licensee MDPI, Basel, Switzerland. This article is an open access article distributed under the terms and conditions of the Creative Commons Attribution (CC BY) license (http://creativecommons.org/licenses/by/4.0/). 